\title{
Diagnostic value of arterial blood gas indices in predicting early neonatal complications
}

\author{
Nayereh Ghomian $^{1}$,Aseyeh Maleki abardeh ${ }^{2}$, Somayeh Moeindarbary $^{3}$, Hoda $_{\text {Bagheri }}{ }^{3}$ \\ 1. Assotiated professor,department of Obstetrics and Gynecology,Neonatal and Maternal Research Center,Mashhad \\ University of Medical Sciences,Mashhad,Iran.Email:ghomiann@mums.ac.ir ORCID ID: 0000-0001-6682-4182 \\ TEL:05138433874 \\ 2. Assistant professor,department of Obstetrics and Gynecology,Neonatal and Maternal Research Center,Mashhad \\ University of Medical Sciences,Mashhad,Iran ORCID ID: 0000-0002-5603-570X \\ 3. Assistant professor,department of Obstetrics and Gynecology,Neonatal and Maternal Research Center,Mashhad \\ University of Medical Sciences,Mashhad,Iran. ORCID ID: 0000-0003-2421-2203 \\ 4. Resident of Obstetrics and Gynecology,Neonatal and Maternal Research Center,Mashhad University of Medical Sciences \\ ORCID ID: 0000-0003-4017-7305
}

ABSTRACT

Background and Aim: The aim of this study was to determine the relationship between cord arterial blood gas $(\mathrm{ABG})$ indices and early neonatal complications in neonates born with fetal distress and also the threshold level of measured values for the risk assessment of complications.

Materials and Methods: 221 mothers with fetal distress who met our inclusion criteria participated in this 12 month cross-sectional study in Mashhad University of Medical Sciences from 2015 to 2016 . Blood samples were taken from umbilical artery of the neonates after birth. Early perinatal complications and their association with $\mathrm{PH}$ and $\mathrm{BE}$ at birth and 8 hours later and also the diagnostic values of the afore mentioned values were evaluated.

Results: 221 pregnant mothers at 37-41 weeks of gestation (mean gestational age of 38 weeks and 4 days) who had developed fetal distress during hospitalization were entered into the study. Seizure $(\mathrm{p}<0 / 01)$, jaundice $(\mathrm{p}<0 / 015)$, gasterointestrinal complication $(\mathrm{p}<0 / 01)$, NICU haspitalization $\geq 1$ week $(p<0 / 001)$ were significantly higher in the neonates with $\mathrm{PH}<7 / 2$. Seizure $(p<0 / 01)$, gastero intestinal complication $(p=0 / 049)$. NICU hospitalization $\geq 1$ weak $(\mathrm{p}<0 / 001)$ were significantly higher in the neonates with $\mathrm{BE}<-14$. The highest diagnostic accuracy rates for respiratory complications $(85 \%)$ was related to BE measured 8 hours after birth. The highest diagnostic accuracy rates for seizure $(88 \%)$ and gastrointestinal $(77 \%)$ complications were related to $\mathrm{PH}$ measured 8 hours after birth. But for renal complications $(82 \%)$ and jaundice $(60 \%)$ it was associated with $\mathrm{PH}$ at birth.

Conclusion: $\mathrm{PH}$ and $\mathrm{BE}$ can be used as reliable predictors for some early neonatal complications.

Keywords: Umbilical cord blood, Blood gas analysis, Fetal distress

Received: Sep 15, 2019

Accepted: Oct 3, 2020

How to cite the article: Nayereh Ghomian,Aseyeh Maleki abardeh,Somayeh Moeindarbary,Hoda

Bagheri. Diagnostic value of arterial blood gas indices in predicting early neonatal complications.

SJKU. 2021;26(3):105-116.

Copyright () 2018 the Author (s). Published by Kurdistan University of Medical Sciences. This is an open access article distributed under the terms of the Creative Commons Attribution-Non -Commercial License 4.0 (CCBYNC), where it is permissible to download, share, remix, transform, and buildup the work provided it is properly cited. The work cannot be used commercially without permission from the journal 


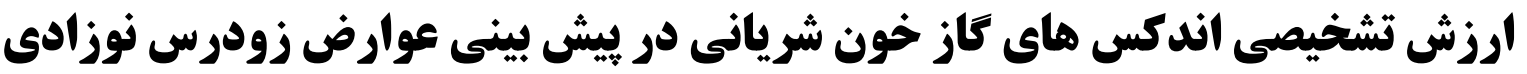

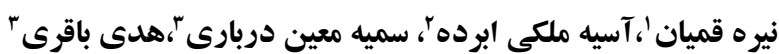

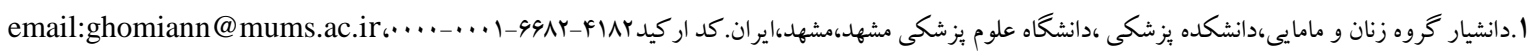

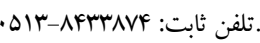

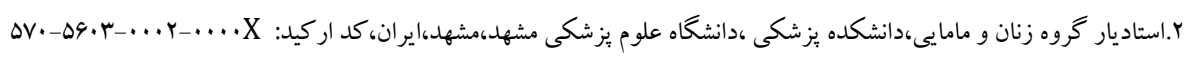

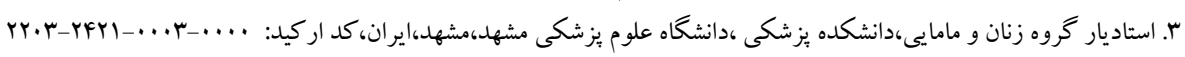

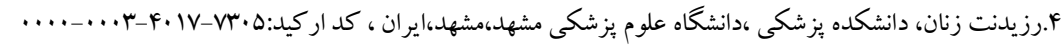

حكيده

زمينه و هدف: اين مطالعه با هدف تعيين ارتباط اند كس هاى كازهاى خون شريانى(ABG) بند ناف با عوارض زودرس نوزادى

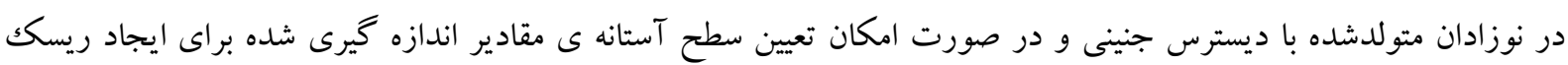
عوارض.انجام مى گردد

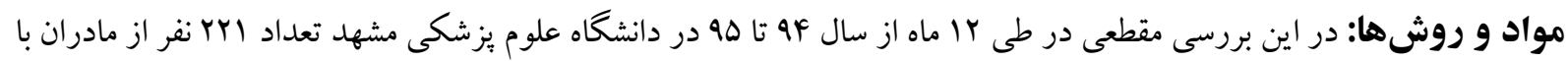

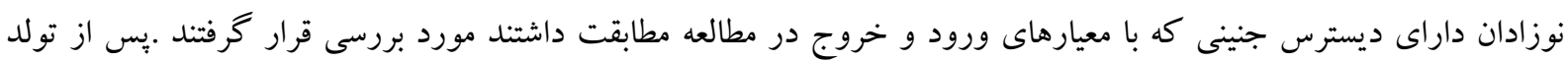

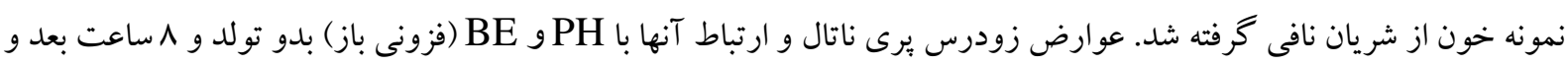
دقت تشخيصى موارد مذكور مورد بررسى قرار گرفت.

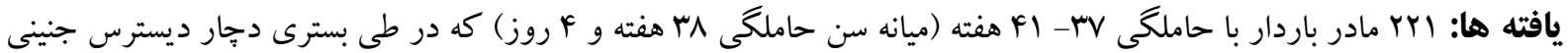

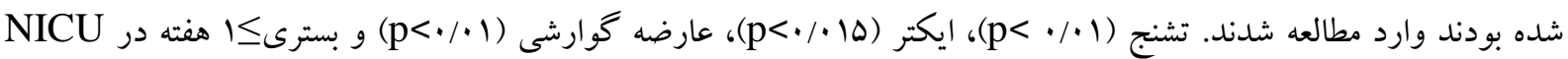

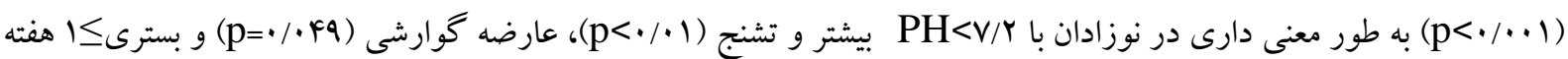
در BEU بيشتر مشاهده شد. بيشترين سطح زير منحنى راك (دقت

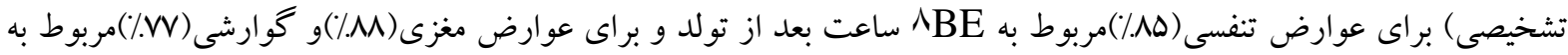

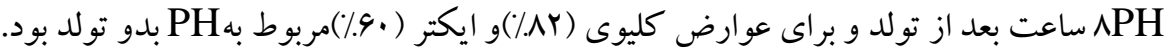

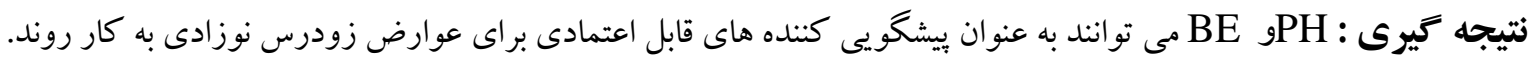

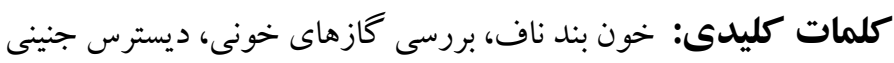


كننده ضعيف براى اختلال نورولوزيكك طولانى مدت برمىشمارند (r). اما درهرحال بيان مى كنند امتياز آبكار

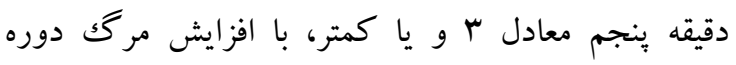
نوزادى و افزايش خطر عواقب نورولوزيكك همر اه است (r). باتوجه به تعريف آسفيكسى به معناى محروميت از اكسيزن،

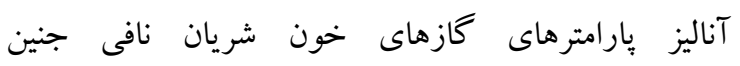
(Arterial blood gas)

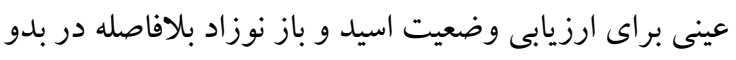

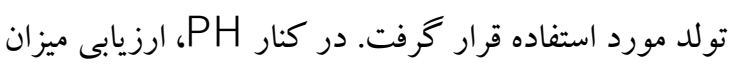

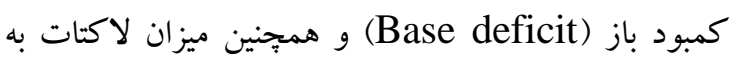
منظور تخمين خطر موربيديتى كوتاهمدت و بلندمدات نوزادى مورد مطالعه و تحقيق قرار گرفته است (4). محققين

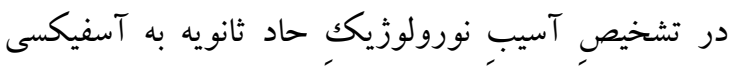

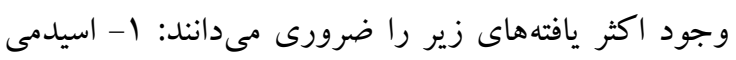
شديد همر اه با PH خون شريان نافى در حد كمتر از V. Y Y-

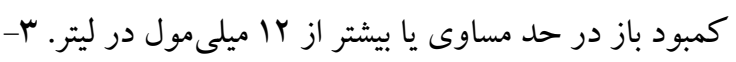

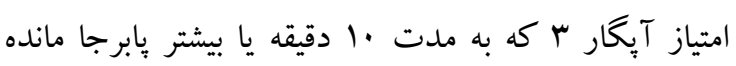

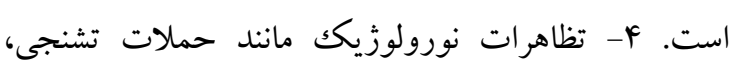

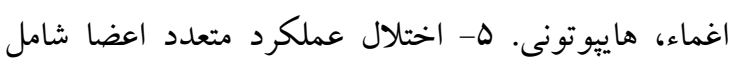

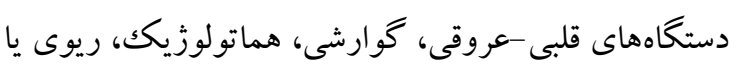
كليوى (r). اما هنوز تحقيقات در جهت تعيين ارتباط ساير ماركرهاى

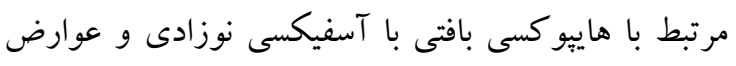
آن ادامه دارد، جنانجه ترويونين T و كراتينين را به عنوان

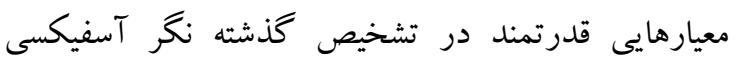

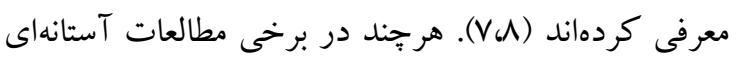

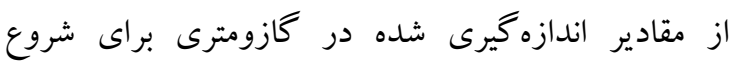
عوارض برى ناتال مانند فلج مغزى بيان شده است، به دليل

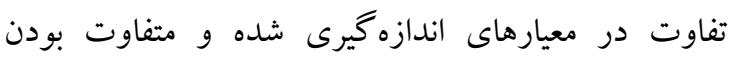

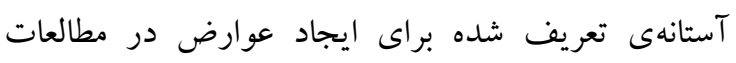

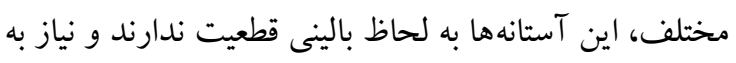
مطالعات گستردهتر، با متدولوزى قوى تر مىباشد. (•961)

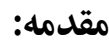

آسفيكسى بريناتال يكى از حونه حوادث بسيار تأسفبار و

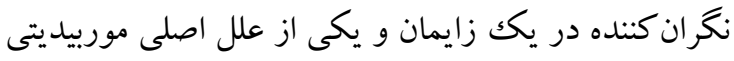
و مورتاليتى نوزادان محسوب مى شود. اين وضعيت در نتيجه اختلال در تبادل كازهاى تنفسى و يا اختلال در تبادلات

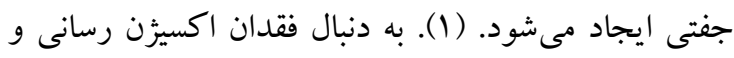

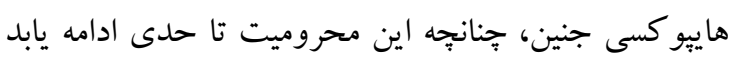

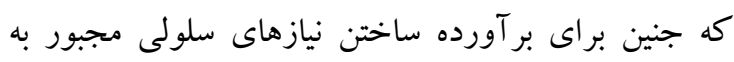

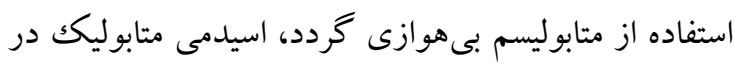

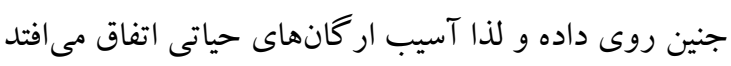

شديدترين عارضة آسفيكسى، هاييو كسيك ايسكميك (T). آنسفالوياتى Hypoxic ischemic ) (encephalophaty و در گيرى مغز به صورت فلج مغزى (f)

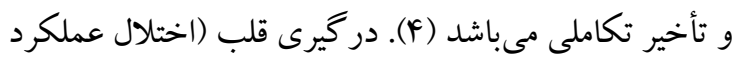
ميو كارد)، كليهها (آسيب حاد كليه)، ريهها (به شكل نارسايى حاد تنفسى) و درگيرى سيستم گوارشى به شكل

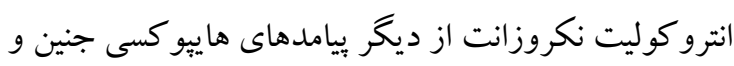

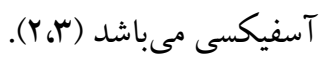

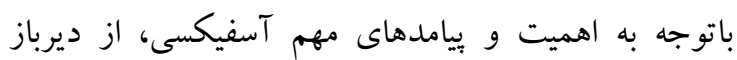
تاكنون جستجو در جهت يافتن معيارهاى تشخيص بالينى و

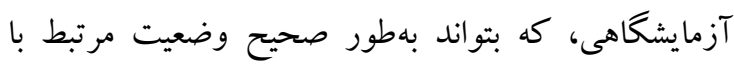
آسفيكسى را توضيح دهند ادامه داشته است. امتياز آيخار

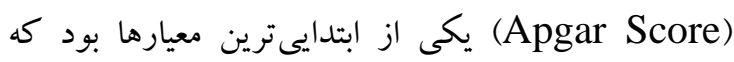
هرجند در سال 190r، ابتدا براى تعيين كودكان نيازمند اقدامات احياء معرفى گرديد(ه) .اما در حال حاضر در كنار

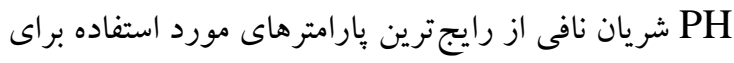
تشخيص نوزادان مبتلا به آسفيكسى مىباشد.

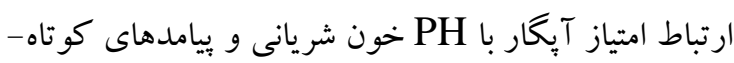
مدت و بلندمدت نوزادى همجنان مورد بحث و اختلاف نظر است. برخى مطالعات ارتباط معنادارى را بين امتياز آيخار

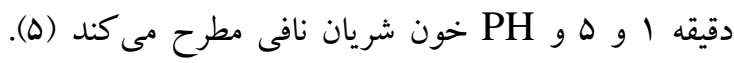

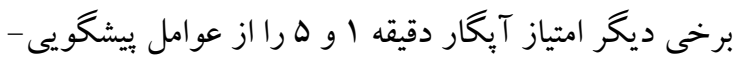


سرنگ هيارينيزه شده كرفته شده و فوراً در شرايط سرد به آزمايشگاه منتقل شد. PH و فزونى باز (BE) بدو تولد و نيز در ^ ساعت بعد از تولد اندازهگيرى شد (مشخصات دستگاه Germany Ziemens,Rapid point 500 مربوط به ارزيابى وضعيت نوزاد شامل آيگار دقيقه اول، آيگار دقيقه ينجم، جنس، وزن، نياز به بسترى در NICU، طول مدت بسترى، ييدايش عوارض تنفسى (تاكى ينه، تعداد تنفس بيش از •و عدد در دقيقه، ديسينه، گر انتينگك و نياز به اكسيثزن بيشتر از r ساعت بعد از تولد)، تشنج، عوارض كوارشى (شامل خونريزى گوارشى)، عوارض كليوى (نارسايى حاد كليه) و ايكتر با ويزيت مكرر نوزاد در NICU آزمونهاى آمارى مناسب ارتباط بين PH و BE بدو تولد و ^ ساعت بعد از تولد با بروز مورتاليتى و عوارض نوزادى ذكر شده بررسى شد و بهترين فاكتور برو گنوستيك براى بيش بينى اين عوارض مشخص گرديد. تحليل دادهها توسط SPSS نسخه 11.5 انجام شد. براى توصيف متغيرهاى كمى از شاخص هاى مركزى و يراكندكى استفاده شد. متغيرهاى كيفى توسط فراوانى و student's T درصد فراوانى كزارش شدند. آزمونهاى Mann-Whitney ،test واليس براى مقايسه ارتباط متغيرهاى كمى با متغيرهاى كيفى مورد استفاده قرار كرفتند. ارتباط دو متغير كيفى توسط آزمون Chi-square ارزيابى شد. براى بررسى همبستخى متغيرهاى كمى از همبستخى بيرسون و اسبيرمن استفاده شد. همجنين شاخص هاى ارزش تشخيصى (حساسيت، ويز گىى، ارزش اخبارى مثبت و منفى) گزارش شد و براى بررسى دقت تشخيصى آزمون (سطح زير منحنى) و تعيين نقطه برش از منحنى راكك استفاده گرديد. سطح معنادارى كمتر از ه • • • درنظر كرفته شد.
باتوجه به شيوع مرگك و مير نوزادان در حد N/9 مورد از هر

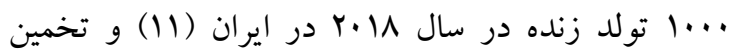
حدود • 1\% از علت مرگكهاى ثانويه به عوارض اوليه برىناتال حاصل از آسفيكسى، اين مطالعه به منظور ارزيابى ارتباط بارامترهاى مختلف خون بند ناف نوزادان متولد شده با ديسترس جنينى با بيامدهاى زودرس وبرىناتال و تعيين بهترين فاكتور برو گنوستيكك براى بيشبينى عوارض زودرس يرىناتال صورت گرفت.

\section{مواد و روشها}

اين مطالعه بهصورت مقطعى و با رويكرد آيندهنگر براى جمع آورى داده ها، در دو بيمارستان آموزشى و دانشگاهى ديارتمان زنان و مامايى مشهد، بعد از تأييد كميته اخلاق (IR.MUMS.fm.REC.1394.291)

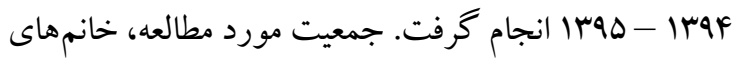

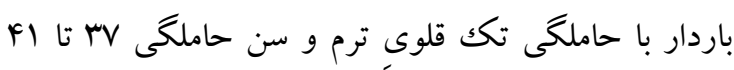
هفته بودند كه در طى بسترى و ختم حاملكَى دجار يكى از انواع ديسترس جنينى (كاهش يا فقدان تحريكتيذيرى ضربان به ضربان، افت ديررس، افت متغير، افت طولانى) مىشدند و در اين افراد هيج علت زمينهاى مانند (يرهاكلايسى، ديابت، بيمارى كليوى، قلبى، دريافت دارو) براى ديسترس جنينى وجود نداشت. نوزادان با ناهنجارىهاى جنينى تشخيص داده شده در بعد از تولد، جنينهاى دجار كاهش رشد داخل رحمى و وجود مكونيوم در مايع آمنيون در بعد از تولد از مطالعه خارج شدند. بر اساس فراوانى مورتاليتى نوزادان به ميزان ·ب٪ در موارد PH كمتر از Vدر مطالعه goldaber و همكاران(Y) و با درنظر گرفتن ه•/ محاسبه شد. از تمام مادران جهت شركت در مطالعه رضايت آكاهانه اخذ شد. در افراد حاضر در مطالعه، بلافاصله بعد از تولد، يك سگمان · •1-Y سانتىمترى از بند ناف دابل كلامب شده و r-1 سى سى خون از شريان نافى توسط يك لك 
كليوى (Y.A.) و ايكتر (·و/) مربوط بهPH بدو تولد بود. مقايسه نمودارهاى راكك براى عوارض تنفسى ،مغزى،

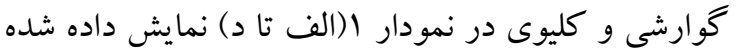

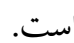

در طى يكك دوره يكك ساله، الY مادر باردار با حاملكى

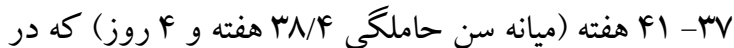
طى بسترى دجار ديسترس جنينى شده بودند وارد مطالعه

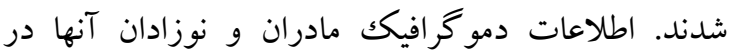
جدول (1) نشان داده شده است. در نوزادان متولد شده با ديسترس جنينى، זrا نوزاد

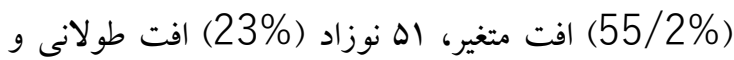
A ن نوزاد (21/7\%) افت ديررس داشتند، كه از اين ميان

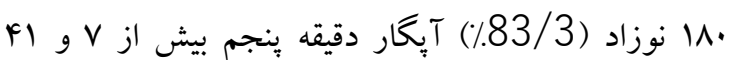
نوزاد (16/7\%) آيگار كمتر از V داشتند. باتوجه به مقالات و با درنظر كرفتن PH كمتر از V/ و BE بيشتر از

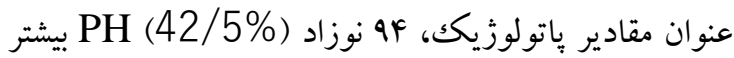

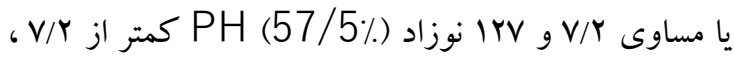

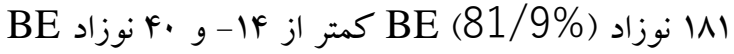

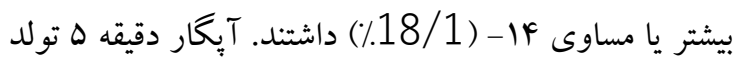
با PH و BE بدو تولد نوزادان ارتباط معنادار داشت تمام نوزادان متولد شده با ديسترس جنينى در بدو تولد براى ارزيابى بيشتر منتقل NICU شدند. در بررسى عوارض نوزادى ايجاد شده، عارضه تنفسى در

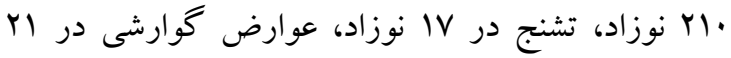
نوزاد و عوارض كليوى در rا نوزاد وجود داشت و 91 نوزاد به بسترى طولانى تر از يكك هفته در NICU نياز يِيدا

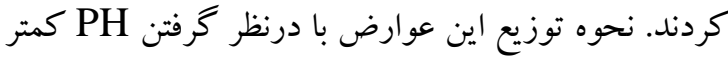

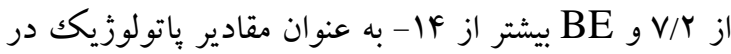
جدول r و ب نشان داده شده است.

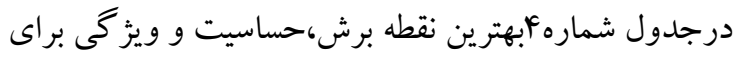

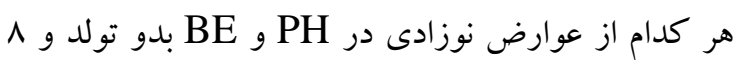
ساعت بعد از تولد مورد بررسى قرار گرفته است. بيشترين

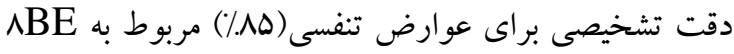

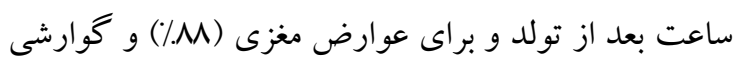

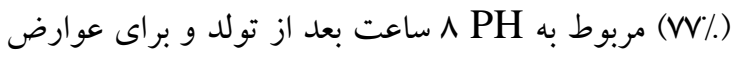


جدول ا.توصيف متغير هاى زمينه اى در مادران و نوزادان

\begin{tabular}{|c|c|c|}
\hline $\mathbf{N}(\%)$ & & متغير \\
\hline \multicolumn{3}{|l|}{ Median $\left(I Q R^{14}\right)$} \\
\hline $38 / 4(38-39)$ & & 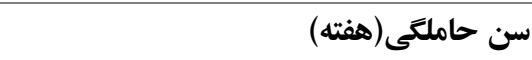 \\
\hline $77(34 / 7 \%)$ & زايمان طبيعى بدون ابزار & روش زايمان \\
\hline $36(16 / 5 \%)$ & زايمان طبيعى با ابزار & \\
\hline $108(49 / 8 \%)$ & سزارين & \\
\hline $30(20-40)$ & & طول مدت ديسترس تا ختم حاملكى(دقيقه) \\
\hline $5(4-6)$ & & طول مدت مرحله اول زايمان(ساعت) \\
\hline $180(83 / 3 \%)$ & $\geq 7$ & 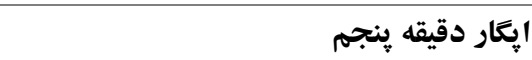 \\
\hline $41(16 / 7 \%)$ & $<7$ & \\
\hline $128(58 / 2 \%)$ & مذكر & 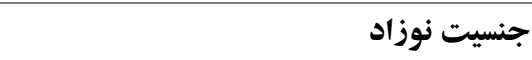 \\
\hline $93(41 / 8 \%)$ & 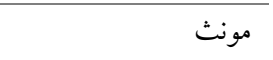 & \\
\hline $60(26 / 8 \%)$ & كرم 2500< & 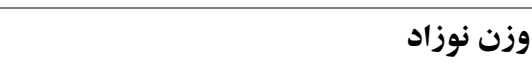 \\
\hline $148(68 / 9 \%)$ & گرم 2500-4000 & \\
\hline $13(4 / 3 \%)$ & خرم 4000> & \\
\hline $116(54 \%)$ & افت متغير & نوع ديسترس \\
\hline $37(16 / 3 \%)$ & 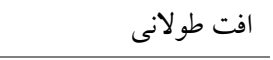 & \\
\hline $21(8 / 6 \%)$ & 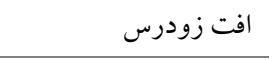 & \\
\hline $47(21 / 1 \%)$ & افت ديررس & \\
\hline
\end{tabular}

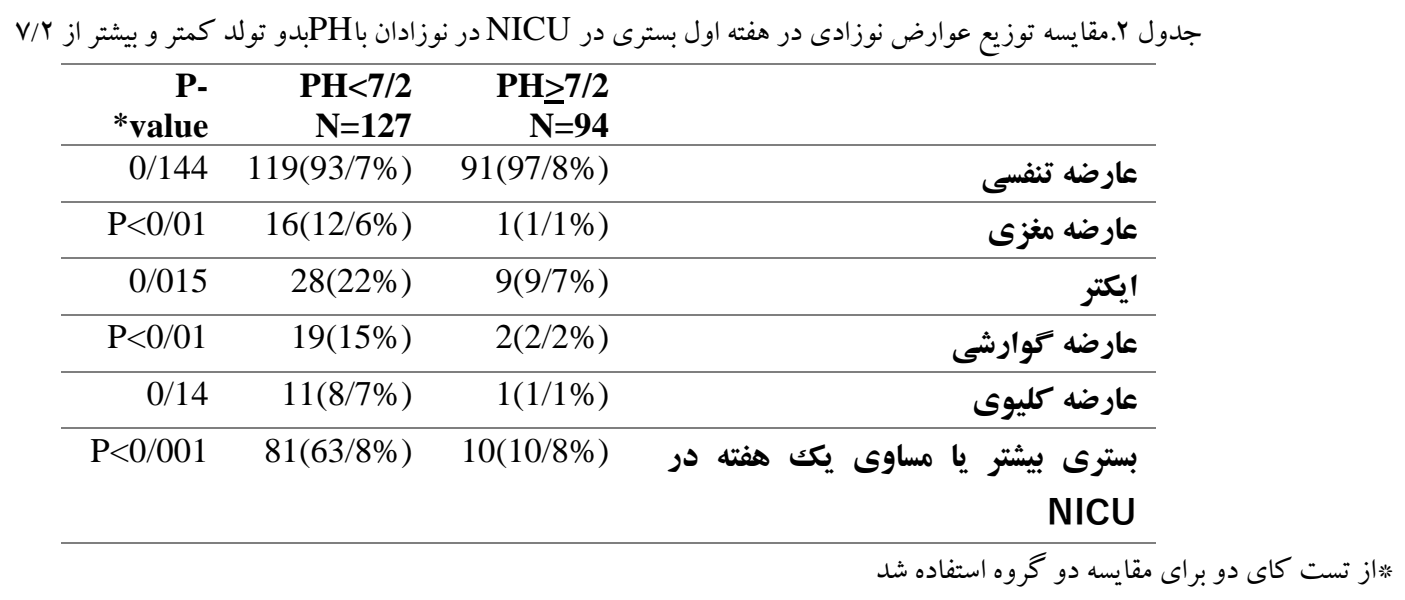


جدول r. مقايسه توزيع عوارض نوزادى در هفته اول بسترى در NICU در نوزادان با BEبدو تولد كمتر و بيشتر از If

\begin{tabular}{|c|c|c|c|}
\hline *P-value & $\begin{array}{r}\mathrm{BE}<-14 \\
\mathrm{~N}=39\end{array}$ & $\begin{array}{r}B E \geq-14 \\
N=182\end{array}$ & \\
\hline $\mathrm{P}<0 / 01$ & $34(87 / 2 \%)$ & $176(97 / 2 \%)$ & عارضه تنفسي \\
\hline $\mathrm{P}<0 / 01$ & $7(17 / 9 \%)$ & $10(5 / 5 \%)$ & عارضه مغزي \\
\hline $0 / 835$ & $7(17 / 9 \%)$ & $30(16 / 6 \%)$ & ايكتر \\
\hline $0 / 049$ & $7(17 / 9 \%)$ & $14(7 / 7 \%)$ & عارضه كوارشي \\
\hline $0 / 145$ & $4(10 / 3 \%)$ & $8(4 / 4 \%)$ & عارضه كليوي \\
\hline $\mathrm{P}<0 / 001$ & $37(94 / 9 \%)$ & $54(29 / 8 \%)$ & مساوي يك هفته در يا \\
\hline
\end{tabular}

ا⿳亠丷厂

جدول F. بهترين نقطه برش و شاخص هاى ارزش تشخيصى متناظر آن براى هر كدام از عوارض نوزادى در PH و بدو تولد و ^ ساعت بعد از تولد

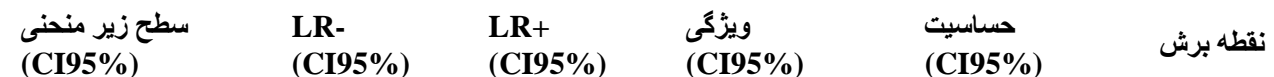

\begin{tabular}{|c|c|c|c|c|c|c|c|}
\hline $\begin{array}{l}0.69 \\
(0.56-0.83)\end{array}$ & $\begin{array}{l}0.62 \\
(0.6-0.7)\end{array}$ & - & $\begin{array}{l}100 \\
(69.2-100)\end{array}$ & $\begin{array}{l}37.8 \\
(31.2-44.7)\end{array}$ & 7.2 & PH 0hr & \multirow{4}{*}{$\begin{array}{l}\frac{y}{3} \\
.3 \\
3 \\
3\end{array}$} \\
\hline $\begin{array}{l}0.76 \\
(0.68-0.84)\end{array}$ & $\begin{array}{l}0.42 \\
(0.4-0.5)\end{array}$ & - & $\begin{array}{l}100 \\
(69.2-100)\end{array}$ & $\begin{array}{l}57.8 \\
(50.9-64.7)\end{array}$ & 7.25 & PH 8hr & \\
\hline $\begin{array}{l}075 \\
(0.61-0.90)\end{array}$ & $\begin{array}{l}0.37 \\
(0.2-0.6)\end{array}$ & $\begin{array}{l}2.47 \\
(1.0-6.4)\end{array}$ & $\begin{array}{l}70.0 \\
(34.8-93.3)\end{array}$ & $\begin{array}{l}74.1 \\
(67.7-80.0)\end{array}$ & -12 & BE 0hr & \\
\hline $\begin{array}{l}0.85 \\
(0.78-0.92)\end{array}$ & $\begin{array}{l}0.33 \\
(0.3-0.4)\end{array}$ & - & $\begin{array}{l}100 \\
(69.2-100)\end{array}$ & $\begin{array}{l}67.4 \\
(6.7-73.8)\end{array}$ & -7 & BE 8hr & \\
\hline $\begin{array}{l}0.78 \\
(0.69-0.87)\end{array}$ & $\begin{array}{l}0.24 \\
(0.09-0.7)\end{array}$ & $\begin{array}{l}3.04 \\
(2.2-4.2)\end{array}$ & $\begin{array}{l}72.9 \\
(66.2-78.9)\end{array}$ & $\begin{array}{l}82.3 \\
(56.6-96.2)\end{array}$ & 7.03 & PH 0hr & \multirow{4}{*}{$\begin{array}{l}\frac{y}{7} \\
.9 \\
: 3 \\
y\end{array}$} \\
\hline $\begin{array}{l}0.88 \\
(0.81-0.95)\end{array}$ & $\begin{array}{l}0.08 \\
(0.01-0.5)\end{array}$ & $\begin{array}{l}3.60 \\
(2.8-4.7)\end{array}$ & $\begin{array}{l}73.8 \\
(67.3-79.8)\end{array}$ & $\begin{array}{l}94.1 \\
(71.3-99.9)\end{array}$ & 7.21 & PH 8hr & \\
\hline $\begin{array}{l}0.79 \\
(0.70-0.87)\end{array}$ & $\begin{array}{l}0.16 \\
(0.04-0.6)\end{array}$ & $\begin{array}{l}3.26 \\
(2.4-4.3)\end{array}$ & $\begin{array}{l}72.9 \\
(66.2-78.9)\end{array}$ & $\begin{array}{l}88.2 \\
(63.6-9.5)\end{array}$ & -11 & BE 0hr & \\
\hline $\begin{array}{l}0.86 \\
(0.80-0.92)\end{array}$ & $\begin{array}{l}0.22 \\
(0.08-0.6)\end{array}$ & $\begin{array}{l}3.98 \\
(2.8-5.6)\end{array}$ & $\begin{array}{l}79.3 \\
(73.1-84.7)\end{array}$ & $\begin{array}{l}82.3 \\
(56.6-96.2)\end{array}$ & -9 & BE 8hr & \\
\hline $\begin{array}{l}0.71 \\
(0.62-0.80)\end{array}$ & $\begin{array}{l}0.25 \\
(0.09-0.7)\end{array}$ & $\begin{array}{l}2.03 \\
(1.6-2.6)\end{array}$ & $\begin{array}{l}57.7 \\
(50.6-64.7)\end{array}$ & $\begin{array}{l}85.7 \\
(63.7-97.0)\end{array}$ & 7.13 & PH Ohr & \multirow{4}{*}{$\begin{array}{l}\frac{y}{3} \\
\cdot 3 \\
3 \\
3 \\
3\end{array}$} \\
\hline $\begin{array}{l}0.77 \\
(0.69-0.85)\end{array}$ & $\begin{array}{l}0.16 \\
(0.04-0.6)\end{array}$ & $\begin{array}{l}2.28 \\
(1.8-2.8)\end{array}$ & $\begin{array}{l}60.3 \\
(53.1-67.2)\end{array}$ & $\begin{array}{l}90.4 \\
(69.6-98.8)\end{array}$ & 7.25 & PH 8hr & \\
\hline $\begin{array}{l}0.70 \\
(0.58-0.82)\end{array}$ & $\begin{array}{l}0.33 \\
(0.2-0.7)\end{array}$ & $\begin{array}{l}2.81 \\
(2.0-3.9)\end{array}$ & $\begin{array}{l}72.8 \\
(66.1-78.9)\end{array}$ & $\begin{array}{l}76.1 \\
(52.8-91.8)\end{array}$ & -11 & BE 0hr & \\
\hline $\begin{array}{l}0.72 \\
(0.61-0.83)\end{array}$ & $\begin{array}{l}0.29 \\
(0.1-0.7)\end{array}$ & $\begin{array}{l}2.40 \\
(1.8-3.2)\end{array}$ & $\begin{array}{l}66.3 \\
(59.3-72.9)\end{array}$ & $\begin{array}{l}80.9 \\
(58.1-94.6)\end{array}$ & -6.5 & BE 8hr & \\
\hline $\begin{array}{l}0.82 \\
(0.71-0.93)\end{array}$ & $\begin{array}{l}0.24 \\
(0.07-0.9)\end{array}$ & $\begin{array}{l}2.63 \\
(1.9-3.6)\end{array}$ & $\begin{array}{l}68.2 \\
(61.5-74.5)\end{array}$ & $\begin{array}{l}83.3 \\
(51.6-97.9)\end{array}$ & 7.04 & PH 0hr & \multirow{4}{*}{$\begin{array}{l}\frac{y}{3} \\
.8 \\
y \\
y\end{array}$} \\
\hline $\begin{array}{l}0.79 \\
(0.70-0.89)\end{array}$ & $\begin{array}{l}0.14 \\
(0.02-0.9)\end{array}$ & $\begin{array}{l}2.19 \\
(1.7-2.8)\end{array}$ & $\begin{array}{l}58.1 \\
(51.2-65.0)\end{array}$ & $\begin{array}{l}91.6 \\
(61.5-99.8)\end{array}$ & 7.25 & PH 8hr & \\
\hline $\begin{array}{l}0.73 \\
(0.61-0.86)\end{array}$ & $\begin{array}{l}0.34 \\
(0.1-0.9)\end{array}$ & $\begin{array}{l}2.94 \\
(2.0-4.4)\end{array}$ & $\begin{array}{l}74.5 \\
(68.0-80.3)\end{array}$ & $\begin{array}{l}75.0 \\
(42.8-94.5)\end{array}$ & -11.5 & BE 0hr & \\
\hline $\begin{array}{l}0.77 \\
(0.62-0.91)\end{array}$ & $\begin{array}{l}0.25 \\
(0.07-0.9)\end{array}$ & $\begin{array}{l}2.55 \\
(1.9-3.5)\end{array}$ & $\begin{array}{l}67.3 \\
(60.5-73.6)\end{array}$ & $\begin{array}{l}83.3 \\
(51.6-97.9)\end{array}$ & -7 & BE 8hr & \\
\hline $\begin{array}{l}0.60 \\
(0.50-0.70)\end{array}$ & $\begin{array}{l}0.49 \\
(0.3-0.9)\end{array}$ & $\begin{array}{l}1.51 \\
(1.2-1.9)\end{array}$ & $\begin{array}{l}50.0 \\
(42.5-57.5)\end{array}$ & $\begin{array}{l}75.6 \\
(58.8-88.2)\end{array}$ & 7.15 & PH 0hr & \multirow[b]{4}{*}{$\overline{\overline{7}}$} \\
\hline $\begin{array}{l}0.54 \\
(0.45-0.64)\end{array}$ & $\begin{array}{l}0.54 \\
(0.3-1.1)\end{array}$ & $\begin{array}{l}1.25 \\
(1.0-1.5)\end{array}$ & $\begin{array}{l}35.1 \\
(28.2-42.6)\end{array}$ & $\begin{array}{l}81.0 \\
(64.8-92.0)\end{array}$ & 7.31 & PH 8hr & \\
\hline $\begin{array}{l}0.57 \\
(0.47-0.67)\end{array}$ & $\begin{array}{l}0.70 \\
(0.5-1.0)\end{array}$ & $\begin{array}{l}1.50 \\
(1.1-2.1)\end{array}$ & $\begin{array}{l}62.0 \\
(54.6-69.2)\end{array}$ & $\begin{array}{l}56.7 \\
(39.5-72.9)\end{array}$ & -9.5 & BE 0hr & \\
\hline $\begin{array}{l}0.53 \\
(0.44-0.63)\end{array}$ & $\begin{array}{l}0.59 \\
(0.3-1.0)\end{array}$ & $\begin{array}{l}1.34 \\
(1.1-1.7)\end{array}$ & $\begin{array}{l}45.6 \\
(38.2-53.1)\end{array}$ & $\begin{array}{l}72.9 \\
(55.9-86.2)\end{array}$ & -4.5 & BE 8hr & \\
\hline
\end{tabular}




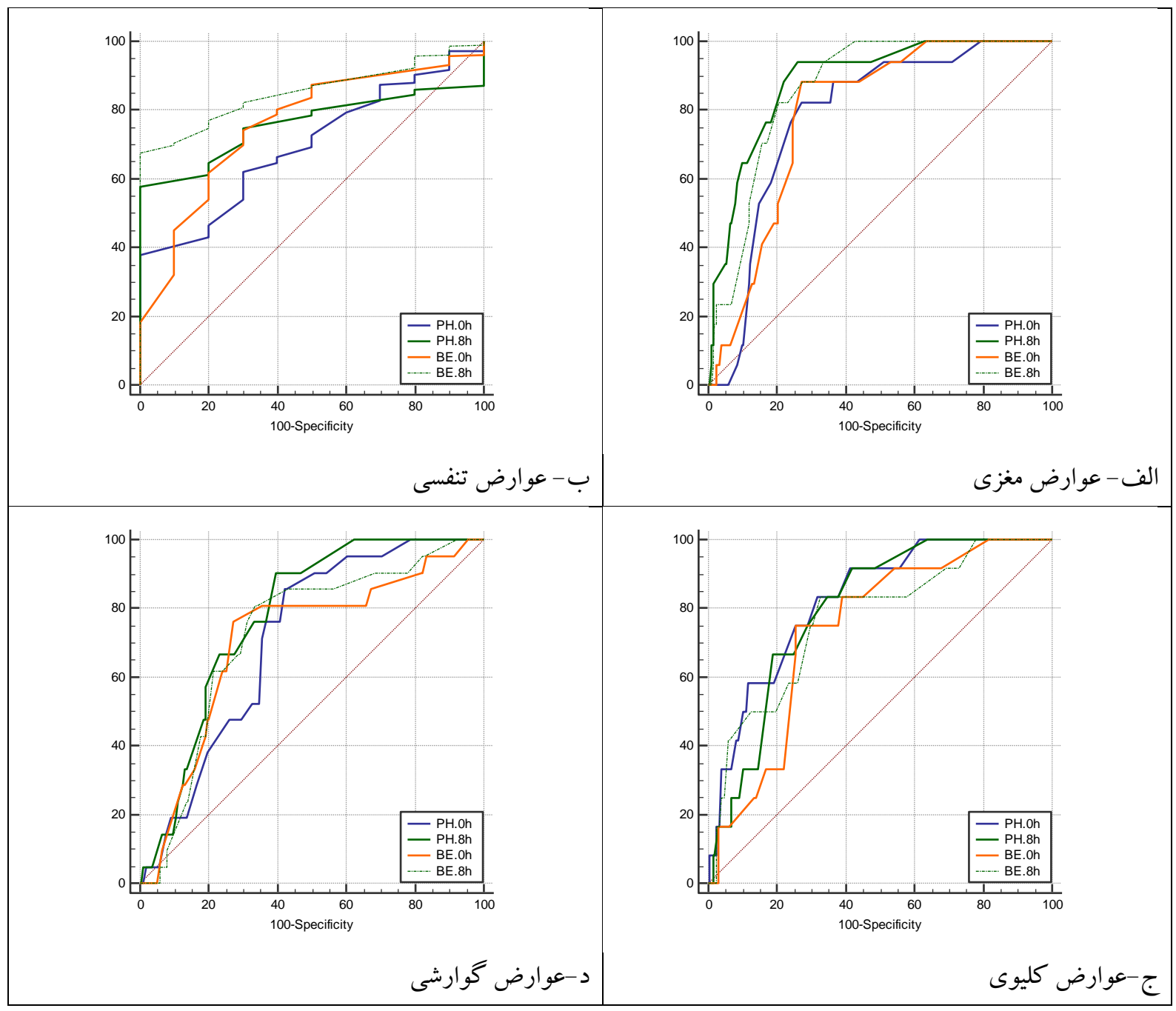

نمودار ا: مقايسه نمودارهاى راكك براى PH و BE در بدو بسترى و ساعت ^براى عوارض تنفسى، مغزى، گوارشى و كليوى 
كرده است (9). دكتر MacLennan و همكاران در سال كمتر از V را در اسيدمى نوزادان بهعنوان آستانه 1999 افزايش اختلالات نورولوزيك مطرح كردند (1ه). درحالى كه Yeh و همكاران در سال rاיץ با بررسى هاه نمونه خون شريانى بند ناف در غالب يك مطالعه

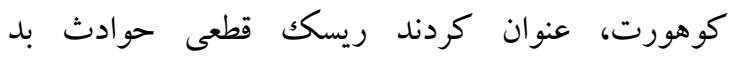

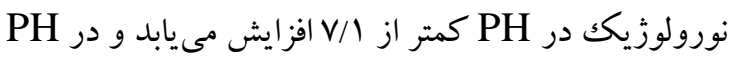

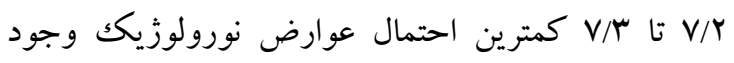

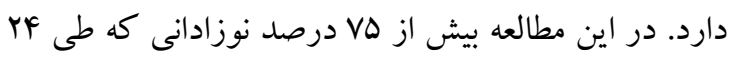

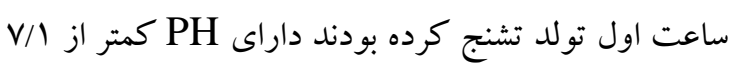

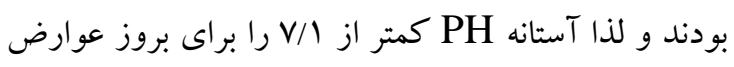
نورولوزيكك مطرح كردهاند (r) . .در مطالعه ما اخرجه

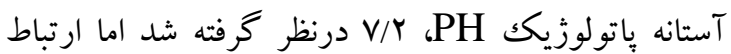
معنادار با اغلب عوارض نوزادى و همجنين عوارض

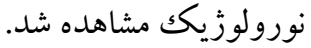
اهميت سنجش كمبود باز به عنوان بررسى جزء متابوليك نيز در كنار PH بايين مورد بحث و بررسى قرار گرفته است. درحالى كه دكتر Cow و همكاران در سال 199V آستانه BE بيشتر يا مساوى r ا را با افزايش خطر متوسط تا شديد فيد عوارض نوزادى مرتبط مىدانند. (19)، دكتر Knutzen و

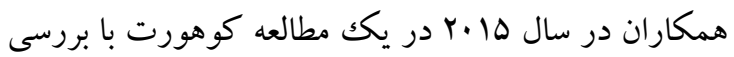

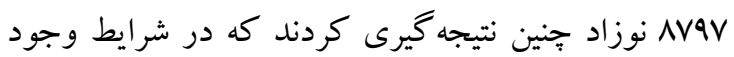
اسيدمى، معيار BD ارزش اضافهترى در ويش گتويى و و

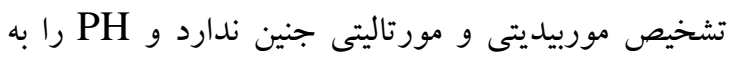
عنوان فاكتور ييش گويى كننده قوى در تمامى عوارض

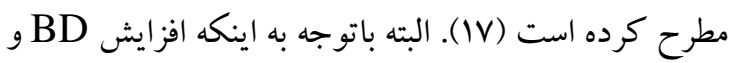

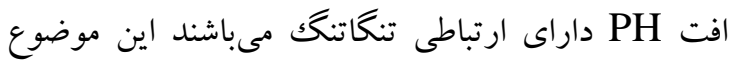

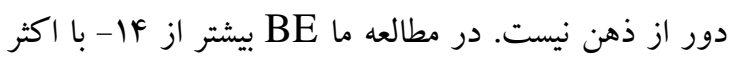
ي تيامدهاى نوزادى مرتبط بود.

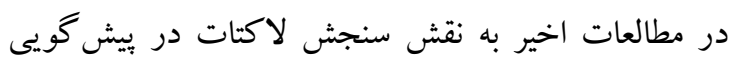

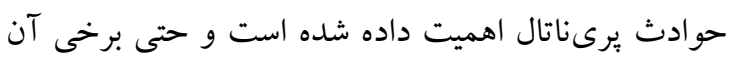
را در شناسايى موربيديتى نوزادى حساستر و اختصاصى تر

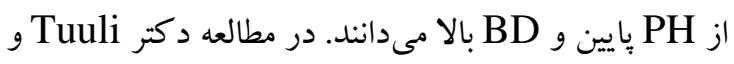

در اين مطالعه با در نظر گرفتن PH كمتر از V/ و

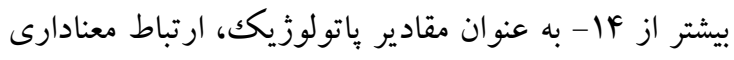
بين PHت كمتر از V/r و بروز اغلب عوارض نوزادى شامل عارضه مغزى، تشنج، عوارض كوارشى و كبدى و نياز به بسترى طولانى در NICU وجود داشت. علىرغم بيشتر بودن عوارض تنفسى در نوزادان با PH بايين ولى ارتباط معنادار آمارى مشاهده نشد. همينطور BE بيشتر از fl با اغلب بيامدهاى بد نوزادى مانند عوارض تنفسى، عوارض

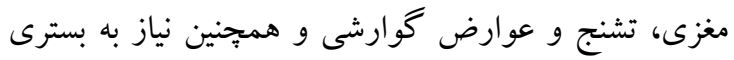
طولانى در NICU مرتبط بود. اين ارتباط تنها در مورد

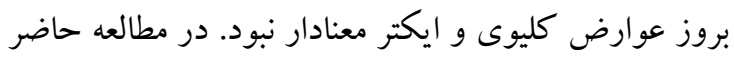
منحنى راكك و بهترين نقطه برش، حساسيت و ويزگ بى براى تشخيص عوارض نوزادى در PH وBE بدو تولد و 1 ساعت بعد مورد بررسى قرار گرفته است كه تا بحال مطالعه

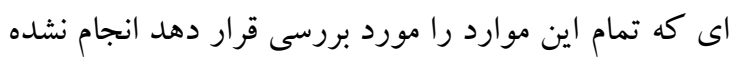
است. اكثر مطالعات به بررسى عوارض مغزى برداخته اند . ارتباط هريكك از شاخص هاى شناخته شده جهت تشخيص

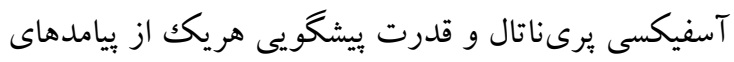

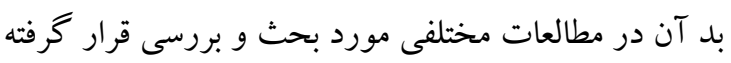

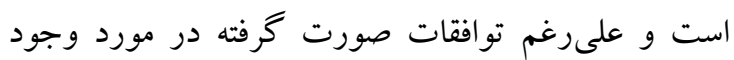
برخى شاخص ها در تشخيص آسفيكسى (r)، هنوز ارزش

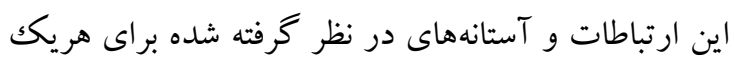
از شاخص ها در مطالعات مختلف متفاوت و متناقض است

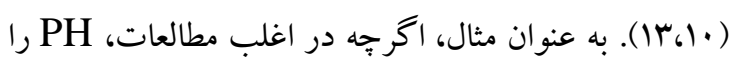

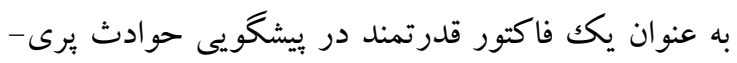

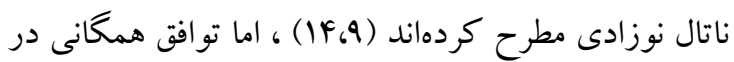

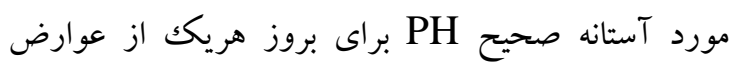
يرىناتال بهدست نيامده است. همينطور يكك مرور نظام مند

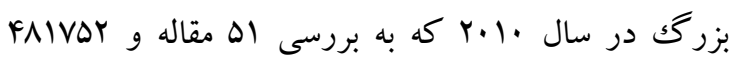
نوزاد يرداخته است، ارتباطى قوى را بين PH بايين خون شريانى و مورتاليتى نوزادى، آنسفالوياتى هاييو كسيك ايسكميك، خون ريزى داخل بطنى، لكومالاسى يرى

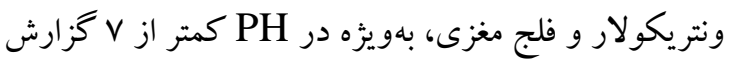

هبمله علمى دانشكاه علوه يِشكى كردستان / دوره بيست و شش / درداد و شهريور م.ع|| 
عار ارزش تشفيص اندكس هاى ...

ذكر شده در بحث، مواردى از نوزادان ترم مشاهده مىشوند كه با وجود معيارهاى آسفيكسى (PH) پايين، آيخار پِايين و افزايش BE) سير نرمال و بدون عارضهاى خواهند داشت

از محدوديت هاى بئوهش، عدم ارسال سريع و به موقع نمونه كرفته شده براى ABG به آزمايشگاه بود.كه در صورت وقوع اين مشكل، نمونه مورد نظر از مطالعه حذف به لمونه مى شد. از نقاط قوت اين مطالعه مى توان به تعيين بهترين نقطه برش، حساسيت و ويزگى براى هر كدام از عوارض نوزادى در PH و BE بدو تولد و ^ ساعت بعد از تولد اشاره كرد كه در مطالعات قبلى جنين بررسى صورت نغر فته بود.

\section{نتيجه Fيرى}

در بررسى ارتباط عوارض زودرس نوزادى با PH و BE بدو تولد و ^ ساعت بعد،. بيشترين دقت تشخيصى براى عوارض تنفسى، مربوط به ABE ساعت بعد از تولد ، براى

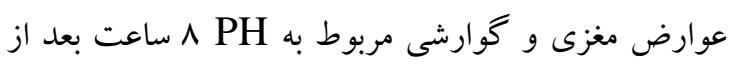
تولد و براى عوارض كليوى و ايكتر مربوط به PH بدو تولد مى باشد.

\section{تشكر و قدردانى}

نويسند كان بر خود لازم مى دانند از حمايت هاى مادى و

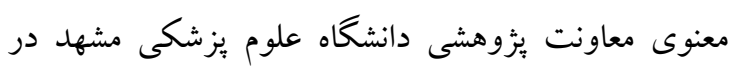

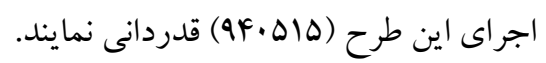

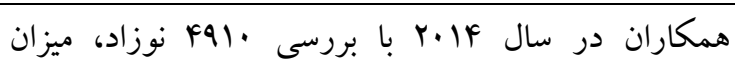

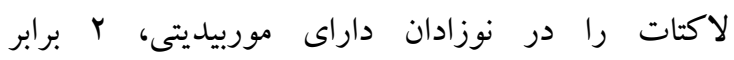
ساير نوزادان گزارش كرده است، درحالى كه ارزش PH را در افتراق اين دو دسته كمرنگگتر دانسته است. لذا علىرغم معرفى آستانه V/Y براى بروز عوارض در مورد PH، لاكتات را در تشخيص بيامدهاى بد نوزادى ارزشمندتر مىداند و حد آستانه آن را ه/ T معرفى مى كنند (1) .اما از سوى ديخر در مطالعه Einikyre و همكاران

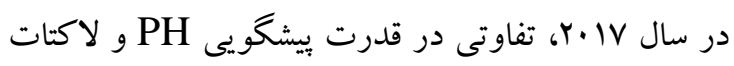
در مورد عوارض كوتاه مدت نوزادى عنوان نشده است (19) .در مطالعه ما سطح لاكتات مورد سنجش قرار نَخرفت. اهميت سنجش نمره آيگار در ارزيابى وضعيت ابتدايى

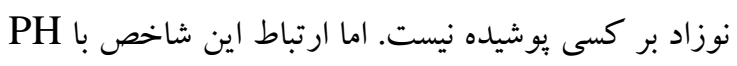

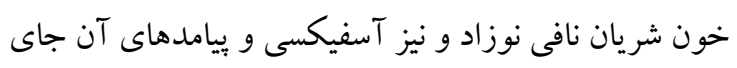

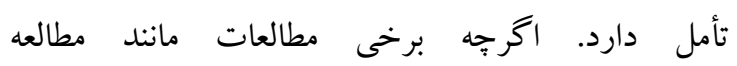

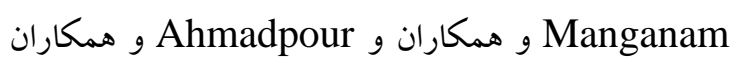
ارتباطى قوى بين نمره آيگار در دقيقه ينجم بعد از تولد با

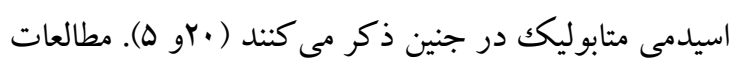
ديخرى مانند مطالعه Anyaegbunam و همكاران نشان

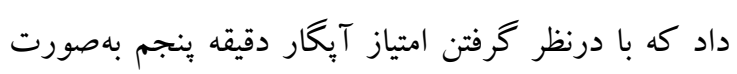
مستقل، امتياز كمتر از V با نياز به يذيرش در NICU و سبسيس مرتبط است، اما در مد نظر قرار دادن امتياز آيخار و

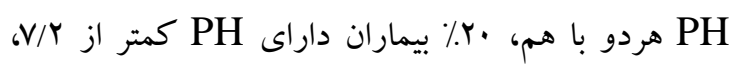
داراى امتياز آيگار بيشتر از V بودند (Y) لدر مطالعه ما، مانند مطالعه Ahmadpour و Manganam ، آيگار دقيقه ه نوزادان با PH و همجِنين با BE ارتباط معنادار داشت. هرجند باتوجه به بالينى بودن ارزيابى نمره آيگار و

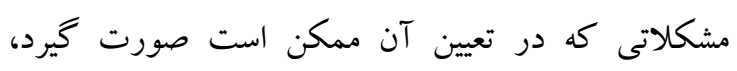
استفاده از آن در جهت تشخيص آسفيكسى بايست با احتياط و در كنار ساير معيارها (BE ، PH و لاكتات) صورت كيرد. جستجو و تحقيق در زمينه ناشناختهاى آسفيكسى همجنان ادامه دارد، گجر اكه علىرغم تمام موارد 
1-Heller G, Schnell R, Misselwitz B, Schmidt S. Umbilical blood pH, Apgar scores, and early neonatal mortality. Z Geburtshilfe Neonatol 2002;207(3):84-9.

2- Beeby PJ, Elliott EJ, Henderson-Smart DJ, Rieger ID. Predictive value of umbilical artery pH in preterm infants. ADC Fetal and Neonatal Edition. 1994;71(2):F93-F6.

3.Ahlin K,Himmelmann k,Nissan S, Sengpiel V, Jacobsson B.Antecedents of cerebral palsy ,according to severity of motor impairment.AOGS 95(7):793,2016.

4- Allen KA1, Brandon DH. Hypoxic Ischemic Encephalopathy: Pathophysiology and Experimental Treatments.Newborn Infant Nurs Rev. 2011 Sep 1;11(3):125-133. PMID: 21927583 PMCID: PMC3171747 DOI: 10.1053/j.nainr.2011.07.004

5- Ahmadpour-Kacho M, Asnafi N, Javadian M, Hajiahmadi M, Taleghani N. Correlation between Umbilical Cord $\mathrm{pH}$ and Apgar Score in High-Risk Pregnancy. Iran J Pediatr. 2010 Dec;20(4):401-6. PMID: 23056738 PMCID: PMC3446088

6- Cahill AG. Umbilical artery pH and base deficit in obstetrics. Am J Obstet Gynecol. 2015 Sep;213(3):257-8. doi: 0.1016/j.ajog.2015.04.036. PMID: 26320373 DOI: 10.1016/j.ajog.2015.04.036

7- oseph S, Kumar S, Ahamed M Z, Lakshmi S. Cardiac Troponin-T as a Marker of Myocardial Dysfunction in Term Neonates with Perinatal Asphyxia. Indian J Pediatr. 2018 Apr 14. doi: 10.1007/s12098-018-2667-3. PMID: 29654572 DOI: 10.1007/s12098-018-26673

8- El-Gamasy MA (2018) Correlation of Renal Function with Severity of Hypoxic Ischemic Encephalopathy (HIE) in Egyptian Full Term Neonates. J Neonat Pediatr Med 4: 157. doi: 10.4172/2572-4983.1000157

9- Malin GL, Morris RK, Khan KS. Strength of association between umbilical cord $\mathrm{pH}$ and perinatal and long term outcomes: systematic review and meta-analysis. Bmj. 2010;340:c1471.

10- Dear P, Newell S, Rosenbloom L, Rennie JM, MacLennan A.Establishing probable cause in cerebral palsy [letter]. BMJ 2000;320:1075.

11- Marandi A, Farrokhzad N, Moradi R, Rezaeizadeh G, Shariat M, Nayeri F. Present Status of the Iranian Newborns' Health, Survival, and Care and Future Challenges. Arch Iran Med. 2019;22(7): 403-409.

12. Goldaber KG, GILSTRAP III LC, Leveno KJ, Dax JS, McINTIRE DD. Pathologic fetal acidemia. Am J Obstet Gynecol . 1991;78(6):1103-7.

13- Yeh P, Emary K, Impey L. The relationship between umbilical cord arterial $\mathrm{pH}$ and serious adverse neonatal outcome: analysis of 51519 consecutive validated samples. BJOG 2012;119:824-831.

14- Prasanna R, Karthikeyan P,Mani M, Paramanantham P, Sekar P. The strength of correlation between umbilical cord $\mathrm{pH}$ and early neonatal outcome. Int $\mathrm{J}$ Contemp Pediatr2016;3:134-7

15- MacLennan A. A template for defining a causal relation between acute intrapartum events and cerebral palsy: international consensus statement. BMJ 1999;319(7216):1054-9.

16- . Low JA, Lindsay BG, Derrick EJ. Threshold of metabolic acidosis associated with newborn complications. Am J Obstet Gynecol 1997;177:1391-4

17- Knutzen L, Svirko E, Impey L. The significance of base deficit in acidemic term neonates. Am J Obstet Gynecol 2015;213:373.e1-7

18- Tuuli MG, Stout MJ, Shanks A, Odibo AO, Macones GA, Cahill AG. Umbilical cord arterial lactate compared with $\mathrm{pH}$ for predicting neonatal morbidity at term. Obstet Gynecol 2014;124:756-61.

هبمله علمى دانشكاه علوم يِشكى كردستان / دوره بيست و شش / درداد و شهريور هع| 
ارغ ارش تشفيص اندكس هاى ...

19- Einikyte R, Snieckuviene V, Ramasauskaite D, Panaviene J, Paliulyte V, Opolskiene G, Kazenaite E. The comparison of umbilical cord arterial blood lactate and $\mathrm{pH}$ values for predicting short-term neonatal outcomes. Taiwan J Obstet Gynecol. 2017 Dec;56(6):745-749. doi: 10.1016/j.tjog.2017.10.007.

20- . Manganaro R, Mami C, Gemelli M. The validity of the Apgar score in the assessment of asphyxia at birth. Eur J Obstet Gynecol Report Biol. 1994;54(2):99-102

21- Amyaegbunam A, Fleischer A, Whihy J, et al.Association between umbilical artery cord pH,five minute Apgar score and neonatal outcome.Gynecol Obstet Invest. 1991;32(4):220-3. 